\title{
Development of Highly Sensitive Immunosensor for Detection of Staphylococcus aureus Based on AuPdPt Trimetallic Nanoparticles Functionalized Nanocomposite
}

\author{
En Han *, Yun Zhang, Jianrong Cai and Xinai Zhang \\ School of Food and Biological Engineering, Jiangsu University, Zhenjiang 212013, China; \\ 18352764521@163.com (Y.Z.); jrcai@ujs.edu.cn (J.C.); zhangxinai@ujs.edu.cn (X.Z.) \\ * Correspondence: enhan@ujs.edu.cn
}

check for updates

Citation: Han, E.; Zhang, Y.; Cai, J.; Zhang, X. Development of Highly Sensitive Immunosensor for Detection of Staphylococcus aureus Based on AuPdPt Trimetallic Nanoparticles Functionalized Nanocomposite. Micromachines 2021, 12, 446. https://doi.org/10.3390/ mi12040446

Received: 19 March 2021 Accepted: 14 April 2021 Published: 16 April 2021

Publisher's Note: MDPI stays neutral with regard to jurisdictional claims in published maps and institutional affiliations.

Copyright: (C) 2021 by the authors Licensee MDPI, Basel, Switzerland. This article is an open access article distributed under the terms and conditions of the Creative Commons Attribution (CC BY) license (https:// creativecommons.org/licenses/by/ $4.0 /)$.

\begin{abstract}
The rapid and sensitive detection of Staphylococcus aureus (S. aureus) is essential to ensure food safety and protect humans from foodborne diseases. In this study, a sensitive and facile electrochemical immunosensor using AuPdPt trimetallic nanoparticles functionalized multi-walled carbon nanotubes (MWCNTs-AuPdPt) as the signal amplification platform was designed for the label-free detection of S. aureus. The nanocomposite of MWCNTs-AuPdPt was prepared by an in situ growth method of loading AuPdPt trimetallic nanoparticles on the surface of MWCNTs. The synthesized MWCNTs-AuPdPt featured good conductivity and superior catalytic performance for hydrogen peroxide. The nanocomposite of MWCNTs-AuPdPt with good biocompatibility and high specific surface area was further functionalized by anti-S. aureus antibodies. The immobilized antibodies could efficiently capture $S$. aureus to the modified electrode by an immune reaction, which resulted in the change of catalytic current intensity to realize the sensitive detection of $S$. aureus. The designed immunosensor could detect $S$. aureus in a linear range from $1.1 \times 10^{2}$ to $1.1 \times 10^{7} \mathrm{CFU} \mathrm{mL}^{-1}$ with a low detection limit of $39 \mathrm{CFU} \mathrm{mL} \mathrm{m}^{-1}$. Additionally, the proposed immunosensor was successfully applied to determine $S$. aureus in actual samples with acceptable results. This strategy provided a promising platform for highly sensitive determination of $S$. aureus and other pathogens in food products.
\end{abstract}

Keywords: trimetallic nanoparticles; electrochemical immunosensor; label-free detection; Staphylococcus aureus

\section{Introduction}

Food safety as a major public health issue has currently attracted widespread attention, which is related to ensuring healthier lives as well as protecting the national economy. Staphylococcus aureus (S. aureus), a typical and dangerous foodborne pathogen, can produce a number of toxins that cause damage to biological membranes by interacting with the host, leading to cell death [1]. S. aureus is recognized for its serious pathogenicity and has become an important source of many diseases, ranging from superficial skin infections to life-threatening systemic diseases such as abscesses, endocarditis, meningitis, and bacteremia [2-4]. Therefore, it is urgent to establish a sensitive and specific method for the detection of $S$. aureus in many fields such as food safety, medical diagnosis, and public health management.

Several methods have been developed for the detection of foodborne pathogens, including culture-based plate counting assays, polymerase chain reaction (PCR), and enzyme linked immunosensor assay (ELISA) [5-7]. The conventional culture methods are time-consuming and laborious, taking several days for results. Although the methods of polymerase chain reaction and enzyme-linked immunosorbent assay are powerful and exact, they need labor-intensive operation, complex sample preparation, specialized equipment, and/or the labeling of antibody, which limit their applications in real sample and rapid determination [8]. Hence, it is of great importance to develop rapid method 
for the detection of $S$. aureus in food samples without complex sample preparation. In recent years, the electrochemical immunosensor with a simplified setup, high sensitivity and specificity has become a new analytical platform for the detection of S. aureus [9-11]. In particular, the label-free electrochemical immunosensor is widely used on account of its simple operation and procedure [12-14].

Nowadays, some nanomaterials with enzymatic properties have received enormous attention due to their superiority of simple preparation, good tunability, and high stability $[15,16]$. Among them, noble metal nanoparticles (such as Au and Pt) have been successfully employed in the construction of electrochemical immunosensors as typical functional nanoenzymes [17]. Compared with single-metal catalysts, trimetallic nanocomposites are generally provided with more excellent properties, such as higher specific surface area and superior catalytic performance [18]. Therefore, trimetallic nanomaterials have been considered of great importance due to their unique features, opening up new horizons for improving the sensitivity of electrochemical immunosensing [19]. In particular, the combination of $\mathrm{Au}, \mathrm{Pd}$, and Pt can exhibit outstanding catalytic activity, chemical stability, and advantageous electrical conductivity [20]. More importantly, immobilization of the nanoenzyme with appropriate carbon materials can greatly increase the catalytic performance for hydrogen peroxide and provide an effective carrier for biomolecule assembly with good biocompatibility and high specific surface area [21-23].

In this work, a label-free electrochemical immunosensor based on AuPdPt trimetallic nanoparticles functionalized multi-walled carbon nanotubes (MWCNTs-AuPdPt) was designed for the rapid and sensitive detection of S. aureus. The nanocomposite of MWCNTsAuPdPt was prepared by an in-situ growth method. The synthesized nanocomposite possessed superior electrochemical catalytic performance toward the reduction of hydrogen peroxide. The MWCNTs-AuPdPt with good biocompatibility and high specific surface area was further applied to immobilize anti-S. aureus antibodies to construct the electrochemical immunosensor. The immobilized antibodies could efficiently capture $S$. aureus to the modified electrode by the specific immune reaction, which resulted in the decrease of catalytic current signal. The decrease magnitude of the current intensity $(\Delta I)$ depended on the number of captured S. aureus. The proposed immunosensor achieved a wide linear range and low detection limit. Additionally, the designed immunosensor was successfully applied to the rapid detection of $S$. aureus in actual samples, providing a novel method for the detection of foodborne pathogens.

\section{Experimental Methods}

\subsection{Reagents and Materials}

Gold chloride tetrahydrate $\left(\mathrm{HAuCl}_{4} \cdot 4 \mathrm{H}_{2} \mathrm{O}\right)$, sodium tetrachloropalladate $\left(\mathrm{Na}_{2} \mathrm{PdCl}_{4}\right)$, platinum chloride hexahydrate $\left(\mathrm{H}_{2} \mathrm{PtCl}_{6} \cdot 6 \mathrm{H}_{2} \mathrm{O}\right)$, L-ascorbic acid, sodium citrate, and polyvinylpyrrolidone (PVP; K-30) were bought from Shanghai Sinopharm Chemical Reagent Co., Ltd. (Shanghai, China). Bovine serum albumin (BSA) and multi-walled carbon nanotubes (MWCNTs) were purchased from Sigma-Aldrich (St. Louis, MO, USA) and Nanjing Xianfeng Nanotech Port Co., Ltd. (Nanjing, China), respectively. S. aureus ATCC 25923 was provided by School of Food \& Biological Engineering, Jiangsu University, and stored with liquid paraffin wax at $4{ }^{\circ} \mathrm{C}$. Anti-S. aureus antibody (Ab) was purchased from Abcam Inc. (Cambridge, UK). All reagents used are analytical reagent grade, and all solutions are prepared with ultra-pure water of millipore $(\geq 18 \mathrm{M} \Omega$, Milli-Q).

\subsection{Apparatus}

Transmission electron microscopy (TEM) images were obtained from JEM-2100 (JEOL Ltd., Tokyo, Japan), and scanning electron microscopy (SEM) pictures were acquired by using Quanta FEG 250 (FEI Ltd., Hillsboro, OR, USA). X-ray photoelectron spectroscopy (XPS) was recorded by AXIS-ULtra DLD (Shimadzu, Japan). All electrochemical measurements were carried out on CHI660D electrochemical workstation (Chenhua Instrument Co., Ltd., Shanghai, China). A three-electrode system was applied in all electrochemical 
experiments, with a glassy carbon electrodes (GCE) as the work electrode, platinum wire as the auxiliary electrode, and a saturated calomel electrode as the reference electrode.

\subsection{Preparation of $M W C N T s-A u P d P t$}

The MWCNTs-AuPdPt nanocomposite was prepared as described in Scheme 1B. First, $20 \mathrm{mg}$ of MWCNTs and $0.1 \mathrm{~g}$ of PVP were initially dispersed in $50 \mathrm{~mL}$ of $\mathrm{HAuCl}_{4}$ $(0.3 \mathrm{mM})$ under constant stirring to obtain a homogeneous dispersion. The mixed solution was continuously boiled with vigorous stirring; then, $1 \mathrm{~mL}$ of trisodium citrate $(1 \%)$ was immediately added to the boiling solution. Subsequently, $2 \mathrm{~mL}$ of ascorbic acid solution $(0.1 \mathrm{M})$ was injected to the above mixture, which was followed by adding $50 \mathrm{~mL}$ of $\mathrm{Na}_{2} \mathrm{PdCl}_{4}$ solution $(0.6 \mathrm{mM})$ and $50 \mathrm{~mL}$ of $\mathrm{H}_{2} \mathrm{PtCl}_{6}$ solution $(0.6 \mathrm{mM})$. After being reacted for $4 \mathrm{~min}$, the black hybrid solution was obtained. Finally, the product was centrifuged at $8000 \times g \mathrm{rpm}$ for $10 \mathrm{~min}$ and washed with ultra-pure water three times; then, it was dried at $60^{\circ} \mathrm{C}$ and stored at $4{ }^{\circ} \mathrm{C}$ for further use.

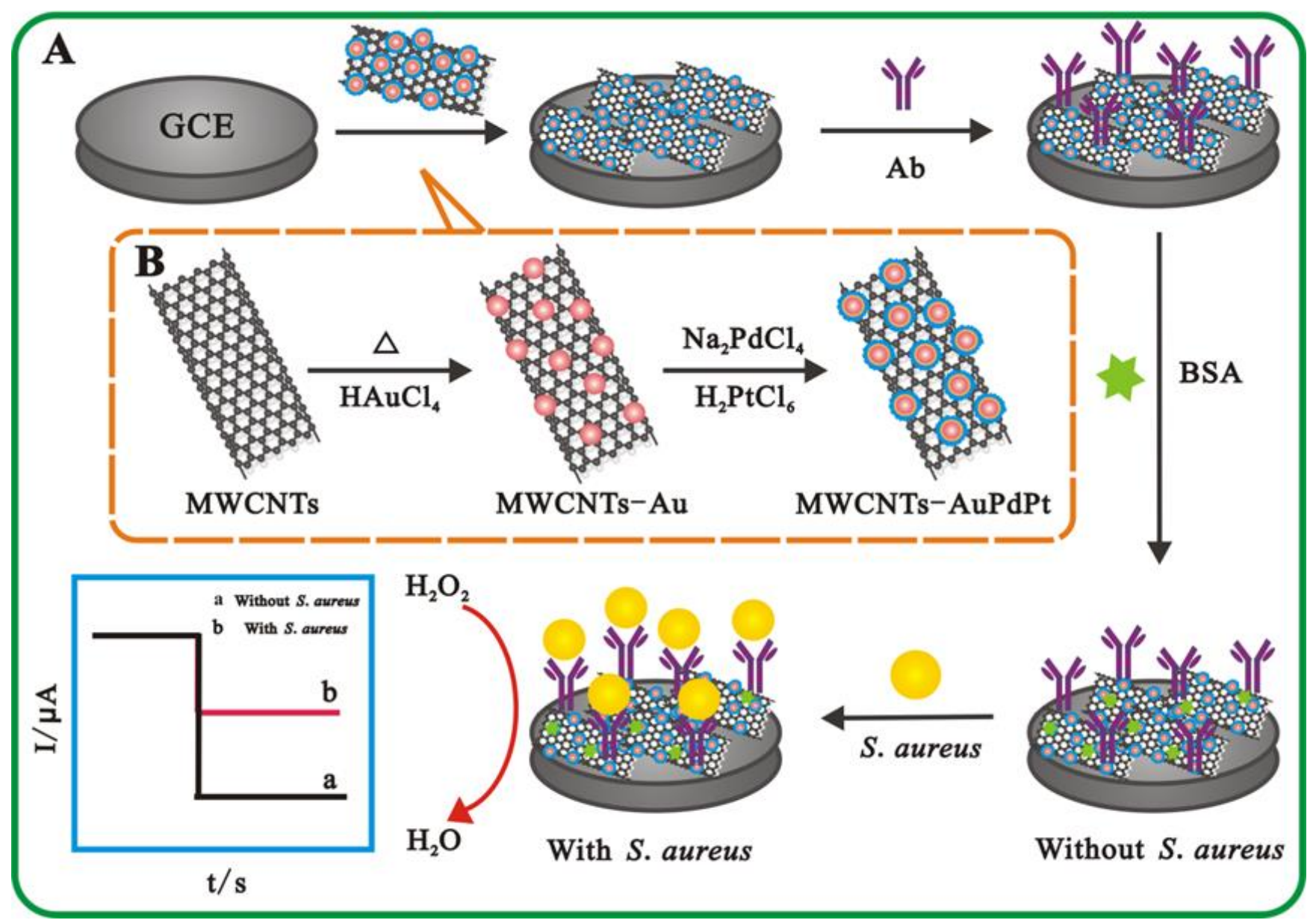

Scheme 1. Schematic description of (A) the fabrication of the electrochemical immunosensor for detection of Staphylococcus aureus (S. aureus), and (B) the preparation procedure of multi-walled carbon nanotubes (MWCNTs)-AuPdPt.

\subsection{Fabrication of the Electrochemical Immunosensor}

The glassy carbon electrodes (GCE) were polished with $0.3 \mu \mathrm{m}$ and $0.05 \mu \mathrm{m} \mathrm{Al}_{2} \mathrm{O}_{3}$ powder on the polishing cloth. Then, GCE were washed thoroughly with $\mathrm{HNO}_{3}(1: 1 \mathrm{v} / \mathrm{v})$, absolute ethanol (95\%) and ultra-pure water, and finally dried in air before use. As shown in Scheme 1A, $10 \mu \mathrm{L}$ of MWCNTs-AuPdPt suspension was dropped to the pretreated electrode surface, which was dried at room temperature. Subsequently, $10 \mu \mathrm{L}$ of $\mathrm{Ab}$ was spread onto the prepared working electrode at $4{ }^{\circ} \mathrm{C}$ for $2 \mathrm{~h}$. Then, the electrode surface was 
rinsed completely with Phosphate-buffered saline (PBS) to remove unsuccessfully bound antibody, followed by dropping $10 \mu \mathrm{L} 1 \%$ BSA solution on the electrode surface for $30 \mathrm{~min}$ to block non-specific reactions. Then, the electrodes were washed with PBS and stored at $4{ }^{\circ} \mathrm{C}$ until use.

\subsection{Electrochemical Determination of S. aureus}

A volume of $10 \mu \mathrm{L}$ of suspension containing different concentration of S. aureus was dropped on the $\mathrm{Ab}$-immobilized electrode and incubated at $37^{\circ} \mathrm{C}$ for $40 \mathrm{~min}$. After careful rinsing with $0.1 \mathrm{M}$ PBS to remove noncaptured cells, the obtained electrode was ready for electrochemical measurement. The amperometric measurement was carried out in $0.1 \mathrm{M}$, $\mathrm{pH}$ 7.4 PBS at a constant potential of $-0.4 \mathrm{~V}$. After the background current stabilized, $\mathrm{H}_{2} \mathrm{O}_{2}$ solution $(20 \mathrm{mM})$ was added to the buffer solution, and the changed current value at this time was recorded.

\section{Results and Discussion}

\subsection{Characterization of MWCNTs-AuPdPt Nanocomposite}

The structure and morphology of the nanocomposite was firstly examined by TEM imaging. Figure 1A illustrated the nanoflower structure of AuPdPt synthesized individually with a mean size of $50 \mathrm{~nm}$. As shown in Figure 1B, MWCNTs had the characteristics of smooth surface and good dispersion, and the average diameter of MWCNTs was about $50 \mathrm{~nm}$. Compared with MWCNTs, Figure 1C showed that numerous AuPdPt trimetallic nanoparticles were universally assembled on the surface of MWCNTs by the in situ growth method, which could be clearly distinguished from AuPdPt and MWCNTs. XPS was further introduced to analyze the elemental composition of MWCNTs-AuPdPt. As shown in Figure 1D, the XPS survey spectrum showed characteristic peaks for $\mathrm{C}, \mathrm{O}, \mathrm{N}, \mathrm{Pt}, \mathrm{Au}$, and $\mathrm{Pd}$. These elements could be further analyzed and determined by peak fitting. According to Figure $1 \mathrm{E}$, the $\mathrm{Pt} 4 \mathrm{f}$ spectrum exhibited two characteristic peaks at $74.61 \mathrm{eV}$ and $71.22 \mathrm{eV}$, which were attributed to $\mathrm{Pt} 4 \mathrm{f} 5 / 2$ and $\mathrm{Pt} 4 \mathrm{f} 7 / 2$, respectively. From Figure $1 \mathrm{~F}$, the peaks of $\mathrm{Au} 4 \mathrm{f} 5 / 2$ and $\mathrm{Au} 4 \mathrm{f} 7 / 2$ could be seen at $87.78 \mathrm{eV}$ and $83.98 \mathrm{eV}$, denoting the successful formation of $\mathrm{Au}$ in the nanocomposite. The high-resolution spectrum of $\mathrm{Pd} 3 \mathrm{~d}$ displayed double peaks at $340.55 \mathrm{eV}$ and $335.12 \mathrm{eV}$, corresponding to the $\mathrm{Pd} 3 \mathrm{~d} 3 / 2$ and $\mathrm{Pd} 3 \mathrm{~d} 5 / 2$, respectively (Figure 1G). The above results were in agreement with previous reports [24,25]. These results further indicated that AuPdPt trimetallic nanoparticles were successfully modified on the surface of MWCNTs.

Due to the synergistic effect of AuPdPt nanoparticles and the MWCNTs, the synthesized MWCNTs-AuPdPt nanozyme was found to have enhanced peroxidase performance. As shown in Figure 1H, the cyclic voltammetry (CV) of GCE/MWCNTs-AuPdPt in the absence of $\mathrm{H}_{2} \mathrm{O}_{2}$ manifested a small current response (curve b), which was approximately $20 \mu \mathrm{A}$ higher than the background current (curve a). When $10 \mathrm{mM} \mathrm{H}_{2} \mathrm{O}_{2}$ was added to the PBS, the detection signal increased dramatically (curve d), and its current signal increased by about $130 \mu \mathrm{A}$ compared with curve b. Hence, it revealed that MWCNTs-AuPdPt could be employed as excellent nanocomposites to construct a label-free electrochemical immunosensor with high sensitivity and realize the amplification of the detection signal of the immunosensor. 

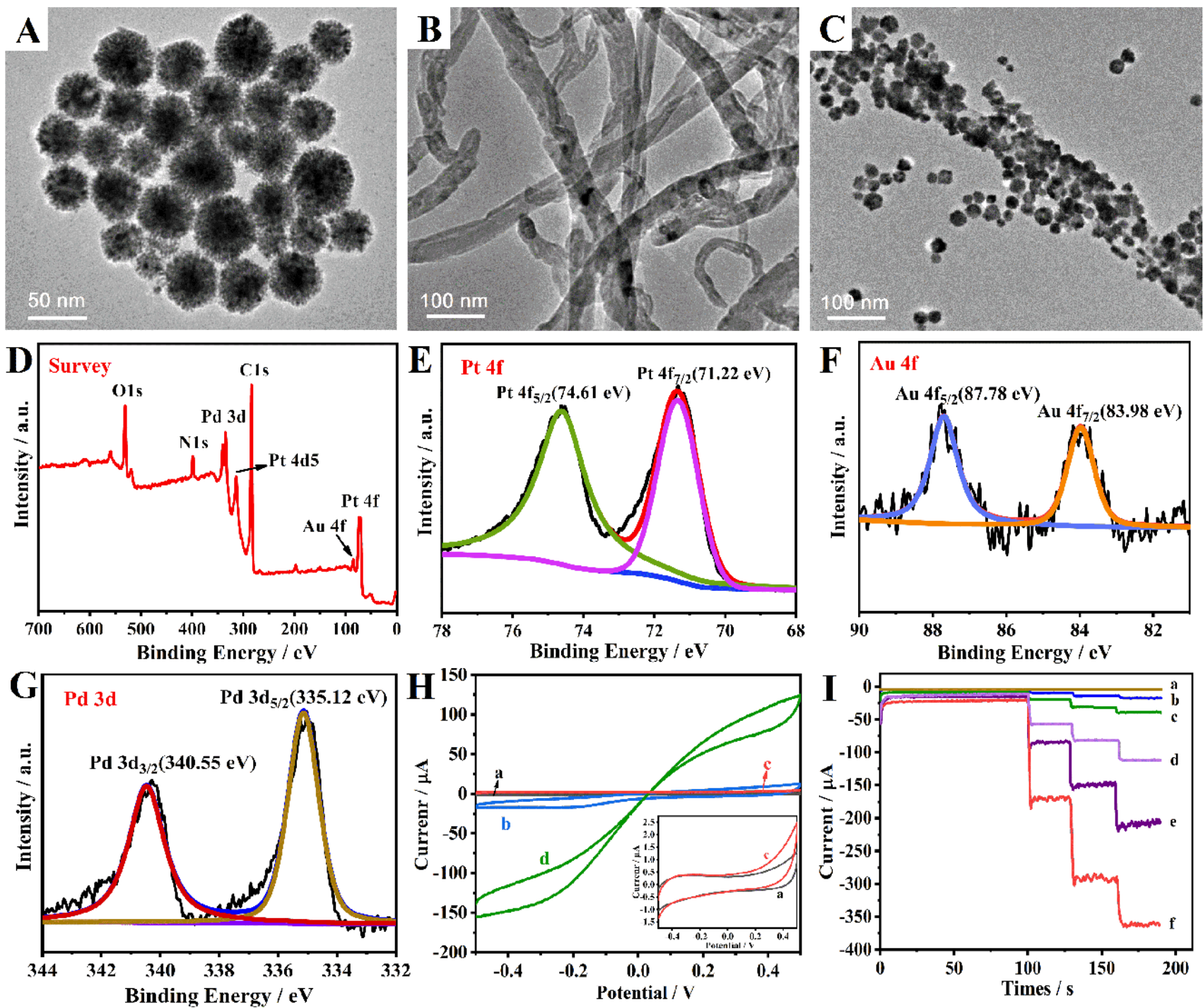

Figure 1. Transmission electron microscopy (TEM) images of (A) AuPdPt, (B) multi-walled carbon nanotubes (MWCNTs), (C) MWCNTs-AuPdPt; (D) X-ray photoelectron spectroscopy (XPS) spectrum of MWCNTs-AuPdPt, high-resolution XPS of (E) Pt 4f, (F) Au 4f, and (G) Pd 3d of the MWCNTs-AuPdPt; (H) cyclic voltammetry (CV) curves of (a) glassy carbon electrodes (GCE) and (b) GCE/MWCNTs-AuPdPt in Phosphate-buffered saline (PBS) solution, and (c) GCE and (d) GCE/MWCNTs-AuPdPt in PBS solution containing $10 \mathrm{mM} \mathrm{H}_{2} \mathrm{O}_{2}$; (I) Ameperometic responses of different modified electrodes for the successive addition of $10 \mathrm{mM} \mathrm{H} \mathrm{O}_{2}$ in PBS solution: (a) GCE, (b) GCE/MWCNTs, (c) GCE/Au, (d) GCE/AuPd, (e) GCE/AuPdPt, and (f) GCE/MWCNTs-AuPdPt. Inset in Figure 1H: the enlarged CVs of curve (a) and (c).

In order to compare the catalytic performance of different modified electrodes, the experiment further investigated the amperometric responses of bare GCE, GCE/MWCNTs, GCE/Au, GCE/AuPd, GCE/AuPdPt, and GCE/MWCNTs-AuPdPt with the continuous addition of $10 \mathrm{mM} \mathrm{H}_{2} \mathrm{O}_{2}$. As represented in Figure 1I, bare GCE had no catalytic effect on the reduction of $\mathrm{H}_{2} \mathrm{O}_{2}$ (curve a), but the current signal slightly improved upon MWCNTs that were modified on the electrode (curve b), which was attributed to the intrinsic peroxidase-like activity of carbon nanotubes [26]. Compared with curve $a, b, c$ and $d$, GCE/AuPdPt (curve e) exhibited good current response on account of the excellent properties of the combination of trimetallic nanocomposites. After MWCNTs-AuPdPt was loaded on the electrode, a significantly increased current signal could be observed (curve f), which was ascribed to the synergistic effect of AuPdPt and MWCNTs. 


\subsection{Characterization of the Electrochemical Immunosensor}

SEM imaging was employed to characterize the morphologies of the different modified electrodes in the process of immunosensor fabrication. As shown in Figure 2A, the MWCNTs with diameters of 50-70 nm displayed a well-dispersed structure in the form of small bundles. Compared with MWCNTs, a denser homogeneous structure with a large number of AuPdPt nanoparticles could be observed for the MWCNTs-AuPdPt nanocomposite film (Figure 2B), indicating the successful preparation of MWCNTs-AuPdPt nanocomposites. As shown in Figure 2C, after the anti-S. aureus antibody was immobilized onto the MWCNTs-AuPdPt film, the tube structure became plumper, and the structure of film was completely changed, confirming that the anti-S. aureus antibody was bound successfully. This three-dimensional nanostructure was in favor of the recognition reaction between the antibody and surface antigen of $S$. aureus. After the immune reaction between $S$. aureus and the anti-S. aureus antibody functionalized on the electrode, the cells of $S$. aureus were largely captured onto the functional electrode (Figure 2D), indicating that the design of immunosensor based on MWCNTs-AuPdPt was feasible.
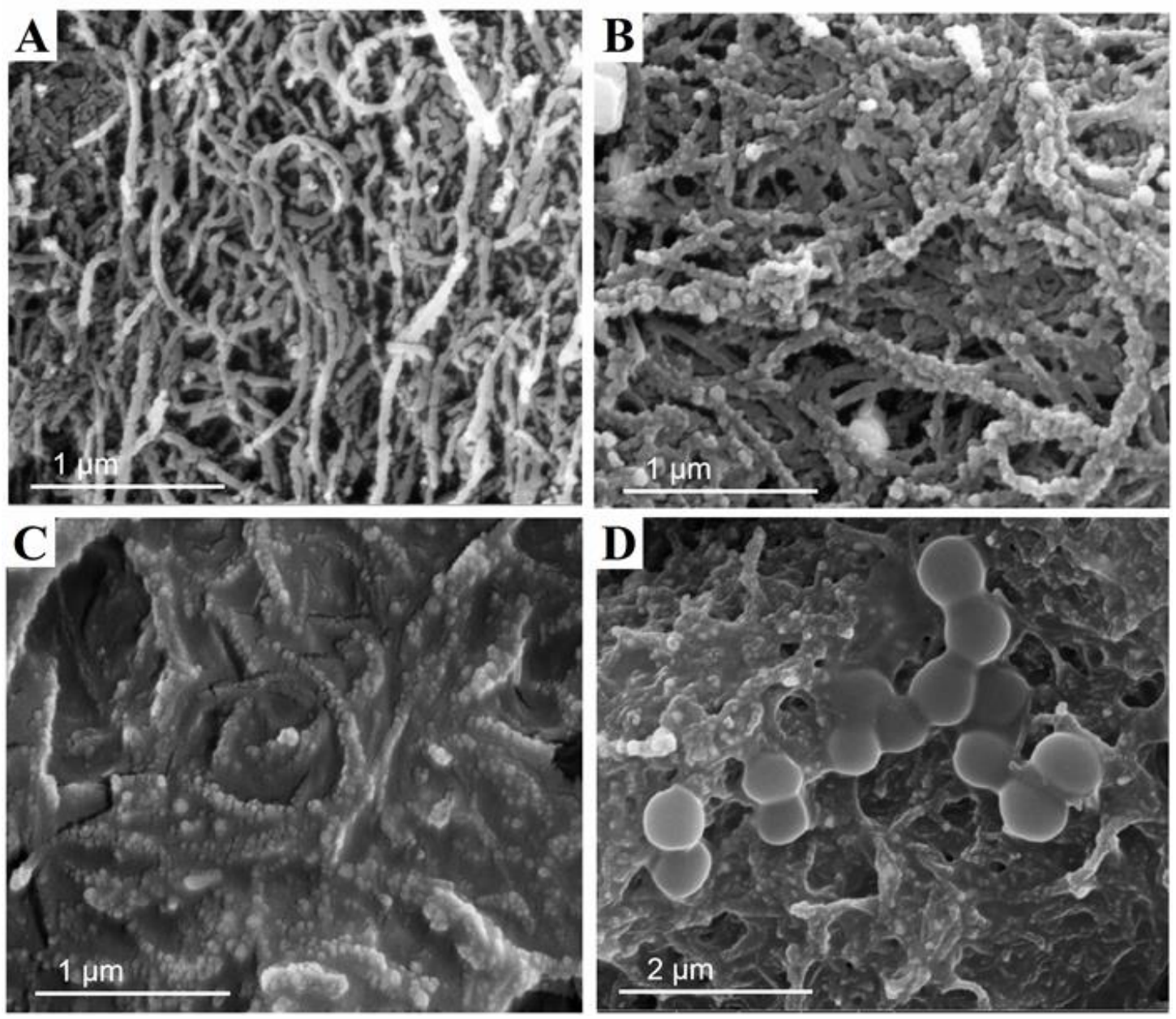

Figure 2. Scanning electron microscopy (SEM) images of (A) MWCNTs, (B) MWCNTs-AuPdPt, (C) MWCNTs-AuPdPt/AntiS. aureus antibody (Ab), and (D) MWCNTs-AuPdPt/Ab/Staphylococcus aureus (S. aureus).

\subsection{Optimization of Experimental Conditions}

In order to obtain excellent analytical performance of the immunosensor, some important parameters such as concentration of antibody and incubation time of $S$. aureus were investigated. The concentration of $S$. aureus for optimization was $1.2 \times 10^{5}$ colony-forming units (CFU)/mL. When one parameter changed, the other parameter was at the optimal 
value. CFU is a measure of viable bacteria or fungal cell numbers in CFU $/ \mathrm{mL}$. It is a way to calculate the number of microorganisms in a sample based on the number of colonies visible to the naked eye on growth medium. The amount of anti-S. aureus antibody on the surface of electrode had a significant effect on the current signal of the electrochemical immunosensor. Therefore, the concentration of the anti-S. aureus antibody used for the capture of S. aureus was investigated. As shown in Figure 3A, the $\Delta I$ value increased with the increasing concentration of antibody from 40 to $100 \mu \mathrm{g} \mathrm{mL}-1$, and it did not change significantly at the concentration of 100 to $140 \mu \mathrm{g} \mathrm{mL}^{-1}$. This phenomenon may be attributed to the fact that the more sites recognized by $S$. aureus with the increase of antibody concentration, but when the antibody concentration was higher than $100 \mu \mathrm{g} \mathrm{mL}^{-1}$, the antibody assembled on the electrode had reached saturation. The optimal concentration of anti-S. aureus antibody was taken as the lowest concentration that yielded saturated cell-binding densities. Therefore, $100 \mu \mathrm{g} \mathrm{mL} \mathrm{m}^{-1}$ was selected as the optimal antibody concentration for the detection of $S$. aureus. The effect of the incubation time for the immune reaction between anti-S. aureus antibody and S. aureus was explored within 10 to $60 \mathrm{~min}$. As shown in Figure 3B, the $\Delta I$ value increased when the reaction time increased from 10 to $40 \mathrm{~min}$, and then, it remained unchanged when the incubation time was more than $40 \mathrm{~min}$, indicating the sufficient binding of anti-S. aureus antibody and S. aureus. Thus, $40 \mathrm{~min}$ was chosen as the optimal immune reaction time.
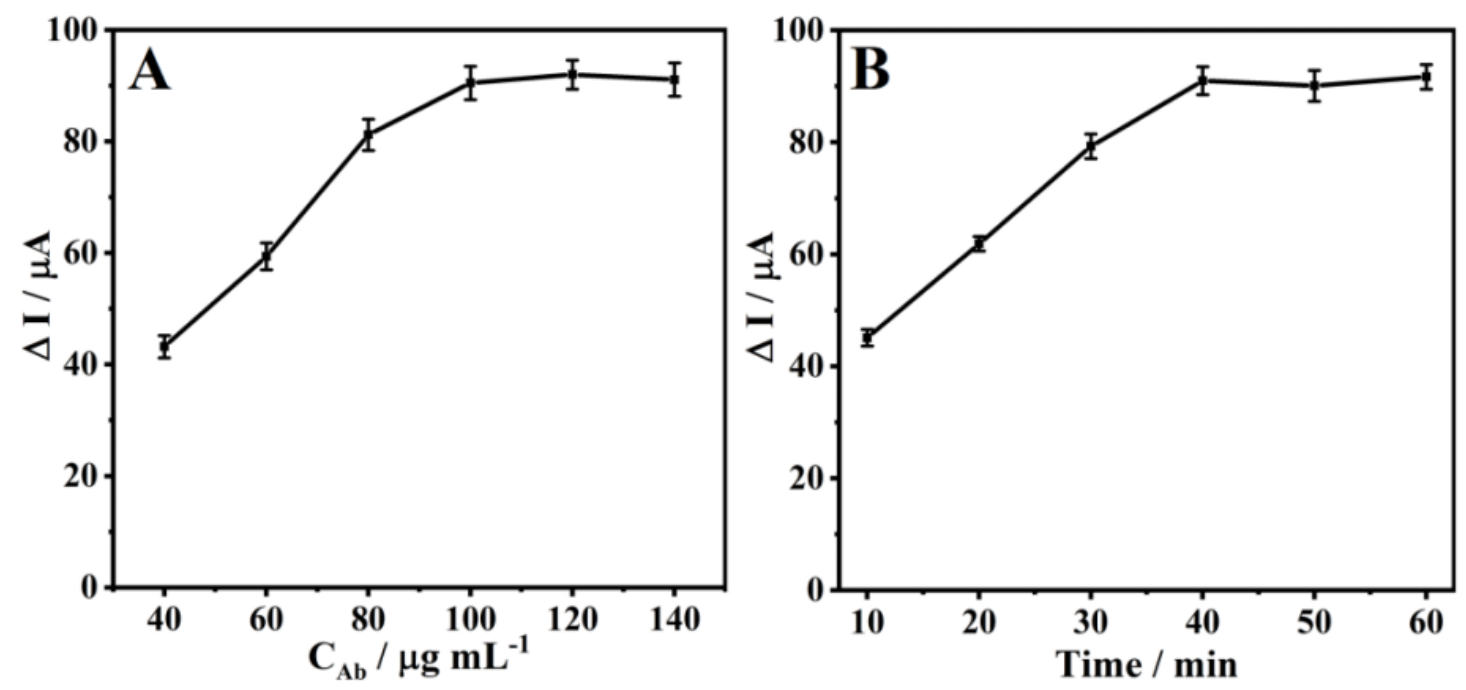

Figure 3. Optimization of the experimental conditions of (A) Ab concentration and (B) incubation time of S. aureus $\left(1.2 \times 10^{5}\right.$ colony-forming units (CFU)/mL).

\subsection{Electrochemical Immunosensor Detection of S. aureus}

Under the optimal condition, the immunosensor exhibited sensitive response to S. aureus in $0.1 \mathrm{M}$ PBS containing $20 \mathrm{mM} \mathrm{H}_{2} \mathrm{O}_{2}$ based on MWCNTs-AuPdPt nanoenzyme. The concentration of $20 \mathrm{mM}$ of $\mathrm{H}_{2} \mathrm{O}_{2}$ was obtained by optimization (not shown here). As shown in Figure 4A, the amperometric response of the electrochemical immunosensor significantly declined with the increase of the concentration of $S$. aureus. This should be due to the fact that with the increase of $S$. aureus concentration, the immune complex formed on the sensing interface enhanced the effect of hindering electron transport, thus reducing the current signal [27]. The calibration curve showed a linear relationship between the $\Delta I$ value and the logarithm of $S$. aureus concentration in the range from $1.1 \times 10^{2}$ to $1.1 \times 10^{7} \mathrm{CFU} \mathrm{mL}{ }^{-1}$ with a low limit of detection of $39 \mathrm{CFU} \mathrm{mL} \mathrm{mL}^{-1}$ (Figure $4 \mathrm{~B}$ ). The linear regression equation of the obtained calibration curve was $\Delta I=20.266 \log C-6.079$ with a correlation coefficient of 0.994 . The limit of detection (LOD) for S. aureus was calculated according to the report based on three times the standard deviation divided 
by the slope of the calibration curve [28]. Furthermore, the analytical performance of the proposed immunosensor for the detection of $S$. aureus was compared with other reports (Table 1). It can be inferred that the fabricated immunosensor in this work exhibited a wider detection range and a lower detection limit. In summary, the label-free electrochemical immunosensor provided a prospective method for the high sensitivity determination of S. aureus, which may be ascribed to the following two factors: (1) The nanocomposite of MWCNTs-AuPdPt with good biocompatibility and high specific surface area provided an excellent platform for loading biomolecules; and (2) the synergistic effect of the prepared MWCNTs-AuPdPt nanozyme showed excellent electrochemical performance and enhanced catalytic activity for $\mathrm{H}_{2} \mathrm{O}_{2}$.
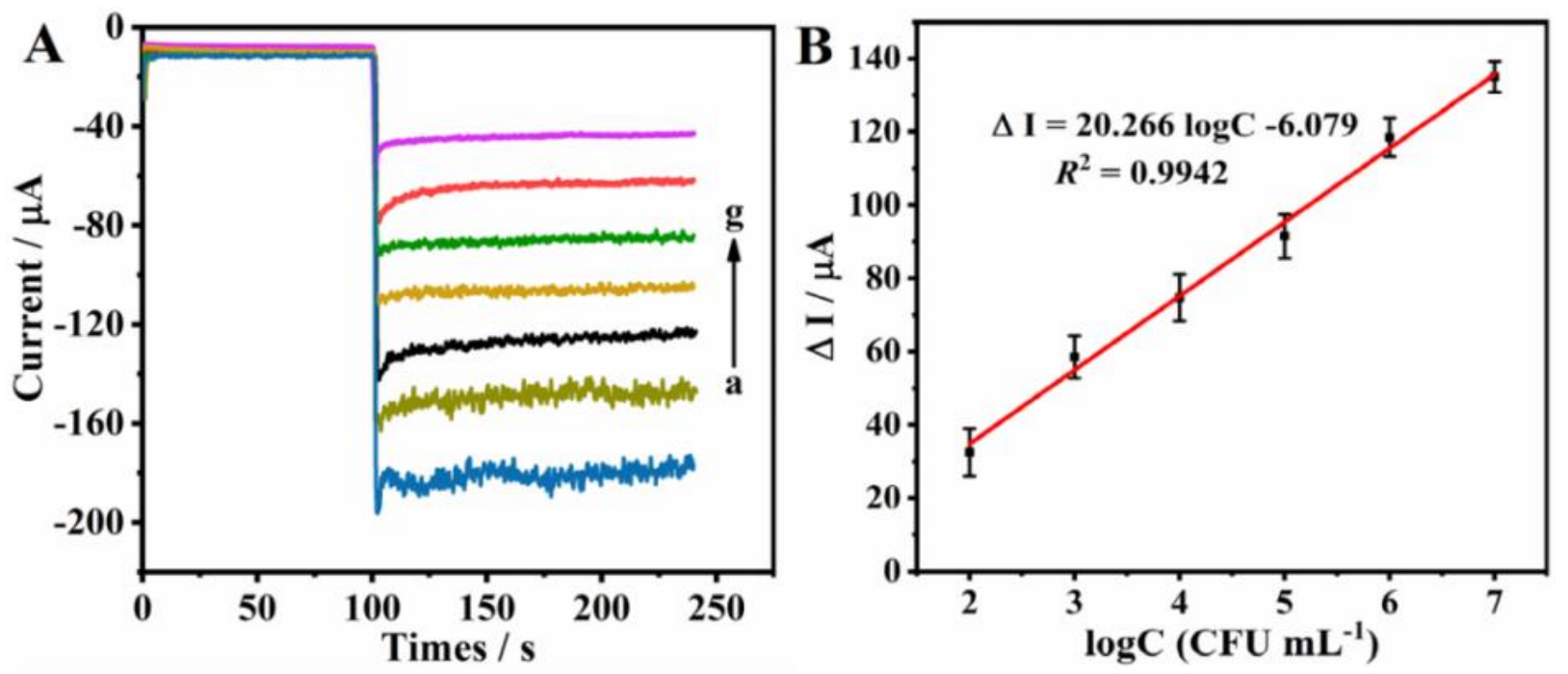

Figure 4. (A) Ameperometic current responses of immunosensor for the detection of different concentrations of $S$. aureus from a to $\mathrm{f}\left(0,1.1 \times 10^{2}, 1.1 \times 10^{3}, 1.1 \times 10^{4}, 1.1 \times 10^{5}, 1.1 \times 10^{6}, 1.1 \times 10^{7} \mathrm{CFU} \mathrm{mL}^{-1}\right)$ in $0.1 \mathrm{M}$ PBS containing $20 \mathrm{mM}$ $\mathrm{H}_{2} \mathrm{O}_{2}$ at $-0.4 \mathrm{~V}$, and (B) plots of $\Delta I$ values vs. logarithm value of the concentrations of $S$. aureus.

Table 1. Comparison of the designed immunosensor for the detection of Staphylococcus aureus (S. aureus) with other studies in the literature.

\begin{tabular}{|c|c|c|c|}
\hline $\begin{array}{c}\text { Substrate of } \\
\text { Immunosensors }\end{array}$ & $\begin{array}{l}\text { Linear Range } \\
\left(\mathrm{CFU} \mathrm{mL}^{-1}\right)\end{array}$ & $\begin{array}{c}\text { Limit of Detection } \\
(\mathrm{LOD})^{3} \\
\left(\mathrm{CFU} \mathrm{mL} \mathrm{L}^{-1}\right)\end{array}$ & Ref. \\
\hline $\mathrm{Ag}-\mathrm{MnO}_{2}$ & $10^{3}$ to $10^{7}$ & - & [29] \\
\hline Magnetic-silica particles & $8.0 \times 10^{2}$ to $1.0 \times 10^{4}$ & $6.8 \times 10^{2}$ & {$[30]$} \\
\hline $\mathrm{Au} / \mathrm{Pt} \mathrm{NCs}^{1}$ & $10^{2}$ to $10^{8}$ & 80 & [31] \\
\hline $\begin{array}{c}\mathrm{AgNPs} / 3 \mathrm{D}-\mathrm{ZnO} \\
\text { nanorods }\end{array}$ & $10^{3}$ to $2 \times 10^{3}$ & $3.3 \times 10^{2}$ & [32] \\
\hline Gold nanodisks & $10^{3}$ to $10^{8}$ & $10^{3}$ & [33] \\
\hline $\mathrm{VAN}^{2}-\mathrm{Au}$ NPs & $10^{3}$ to $10^{8}$ & $10^{3}$ & {$[34]$} \\
\hline MWCNTs-AuPdPt & $1.1 \times 10^{2}$ to $1.1 \times 10^{7}$ & 39 & This work \\
\hline
\end{tabular}

${ }^{1}$ NCs: nanoclusters; ${ }^{2}$ VAN: vancomycin; ${ }^{3}$ LOD: limit of detection.

\subsection{Reproducibility, Stability, and Specificity of the Immunosensor}

The specificity of the immunosensor was analyzed by adding the same concentration of interfering bacteria such as E. coli, V. parahaemolyticus, L. monocytogenes, and B. subtilis $\left(2.4 \times 10^{5} \mathrm{CFU} \mathrm{mL}{ }^{-1}\right)$. As shown in Figure 5, the $\Delta I$ value of $S$. aureus was considerably higher than that of other interference groups. It was worthwhile that when the immunosensor was used to detect the mixture of $S$. aureus $\left(1.8 \times 10^{5} \mathrm{CFU} \mathrm{mL}^{-1}\right)$ and interfering 
bacteria $\left(2.4 \times 10^{5} \mathrm{CFU} \mathrm{mL} \mathrm{m}^{-1}\right)$, the $\Delta I$ value was increased obviously, indicating that the immunosensor was highly selective for the detection of S. aureus.

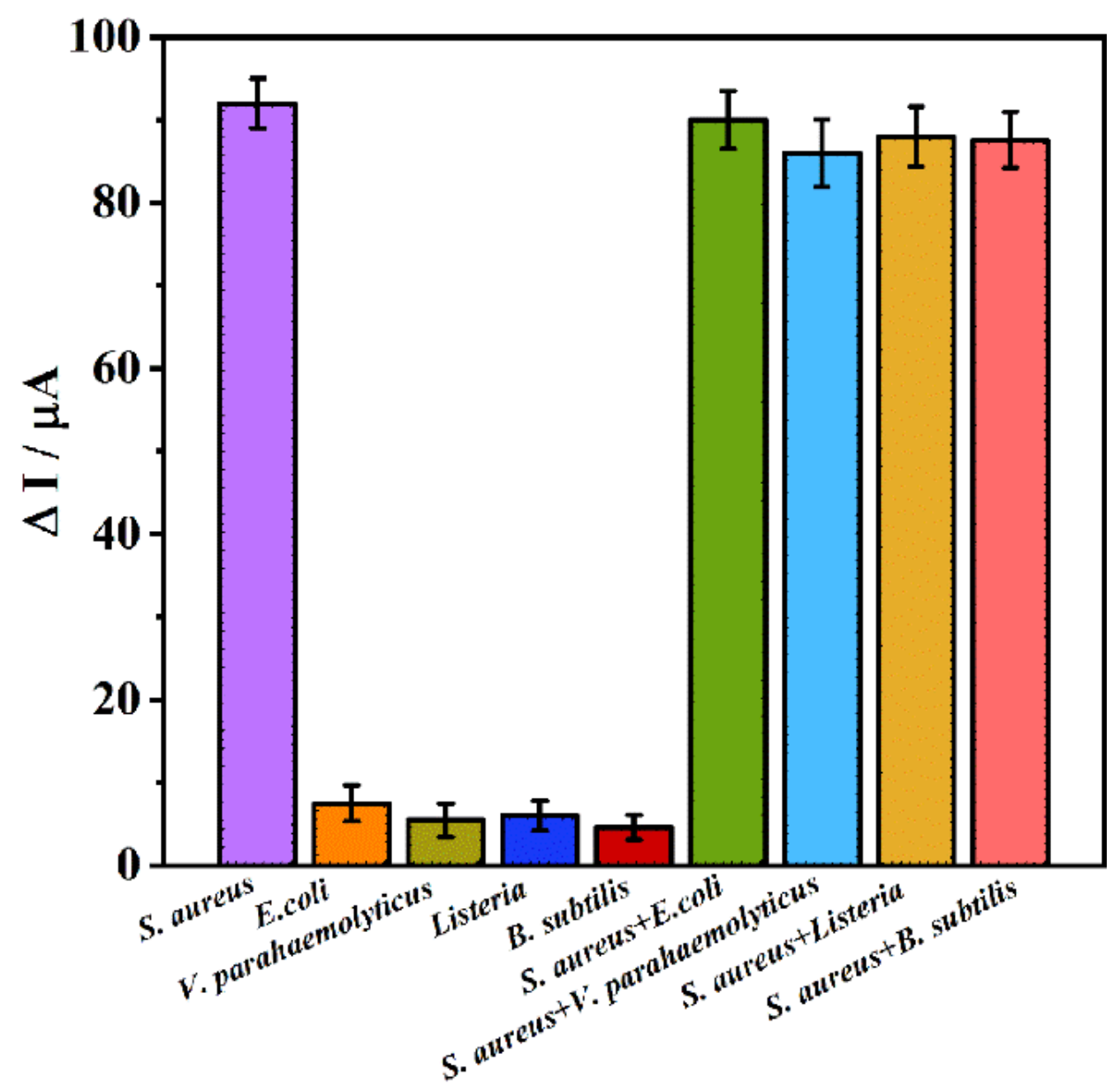

Figure 5. Specificity investigation of the immunosensor to different microorganisms. The concentration of the interfering bacteria is $2.4 \times 10^{5} \mathrm{CFU} \mathrm{mL}{ }^{-1}$.

To examine the reproducibility of the designed immunosensor, eight different electrodes were prepared at the same time to fabricate immunosensors for the detection of $1.5 \times 10^{4} \mathrm{CFU} \mathrm{mL} \mathrm{m}^{-1}$ of $S$. aureus. The relative standard deviation (RSD) of the detection results for the eight electrodes was found to be $6.3 \%$, suggesting the good reproducibility of the immunosensor. In addition, the stability of the developed immunosensor was also studied for the detection of $1.5 \times 10^{4} \mathrm{CFU} \mathrm{mL}{ }^{-1}$ of $S$. aureus. When the immunosensor was stored at $4{ }^{\circ} \mathrm{C}$ in a refrigerator, the current response still remained at $91 \%$ of the original response after a storage period of 3 weeks. The experimental result denoted that the stability of the immunosensor was acceptable.

\subsection{Determination of S. aureus in Real Samples}

In order to demonstrate the potential application of this immunosensor in the analysis of actual samples, the designed immunosensor was applied in the detection of $S$. aureus spiked in three kinds of samples (yogurt, pure milk, and milk powder) with a standard addition method. Pure milk was the boxed milk purchased from the local supermarket. Milk powder sample was first dissolved in PBS; then, it was heated and stirred until it was completely dissolved, while the other two samples did not need further treatment except for the dilution step. These analyses were performed for three times under the same conditions, and the results listed in Table 2 were also compared with the traditional plate count method. The recoveries of standard additions for S. aureus in the spiked samples 
were in the range of $91.2-103.0 \%$ with the RSD of $4.9-7.5 \%$. The above results demonstrated that the developed biosensor was provided with high accuracy and satisfactory application potential, and it could be employed for the detection of S. aureus in the field of food monitoring.

Table 2. Determination of $S$. aureus in real samples by using the immunosensor and plate count method $(n=3)$.

\begin{tabular}{cccccc}
\hline Samples & $\begin{array}{c}\text { Spiked } \\
\left(\mathbf{C F U} \mathbf{~ m L}^{-1}\right)\end{array}$ & $\begin{array}{c}\text { Found } \\
\left(\mathbf{C F U} \mathbf{~ m L}^{-1}\right)\end{array}$ & $\begin{array}{c}\text { Plate Count } \\
\left(\mathbf{C F U} \mathbf{~ m L}^{-1}\right)\end{array}$ & $\begin{array}{c}\text { RSD } \\
\mathbf{( \% )}\end{array}$ & $\begin{array}{c}\text { Recovery } \\
\mathbf{( \% )}\end{array}$ \\
\hline \multirow{2}{*}{ Yogurt } & $2.32 \times 10^{3}$ & $2.39 \times 10^{3}$ & $2.36 \times 10^{3}$ & 6.1 & 103.0 \\
& $2.32 \times 10^{4}$ & $2.19 \times 10^{4}$ & $2.28 \times 10^{4}$ & 7.5 & 94.4 \\
& $2.32 \times 10^{5}$ & $2.23 \times 10^{5}$ & $2.33 \times 10^{5}$ & 6.2 & 96.1 \\
\hline \multirow{2}{*}{ Pure milk } & $3.41 \times 10^{3}$ & $3.45 \times 10^{3}$ & $3.48 \times 10^{3}$ & 5.6 & 101.2 \\
& $3.41 \times 10^{4}$ & $3.26 \times 10^{4}$ & $3.36 \times 10^{4}$ & 4.9 & 95.6 \\
\hline \multirow{2}{*}{ Infant milk } & $3.41 \times 10^{5}$ & $3.30 \times 10^{5}$ & $3.43 \times 10^{5}$ & 5.8 & 96.8 \\
powder & $2.95 \times 10^{3}$ & $2.69 \times 10^{3}$ & $3.05 \times 10^{3}$ & 6.8 & 91.2 \\
& $2.95 \times 10^{4}$ & $2.85 \times 10^{4}$ & $2.88 \times 10^{4}$ & 5.9 & 96.6 \\
\hline
\end{tabular}

\section{Conclusions}

A novel electrochemical immunosensor has been successfully fabricated for the label-free and highly sensitive determination of S. aureus by using the MWCNTs-AuPdPt nanocomposite. The nanocomposite of MWCNTs-AuPdPt prepared by an in situ growth method combines the two advantages of AuPdPt nanoparticles and MWCNTs, which include good conductivity, high specific surface area for loading protein molecules, and superior catalytic performance toward the reduction of hydrogen peroxide. The developed electrochemical immunosensor for assay of S. aureus with a broad linear range and a low detection limit has been demonstrated to possess perfect specificity, high sensitivity, and acceptable reproducibility. Additionally, this novel electrochemical immunosensor is successfully applied to determine S. aureus in food samples without complicated sample pretreatment. Therefore, this strategy is of great significance for the rapid and highly sensitive detection of $S$. aureus in actual food samples.

Author Contributions: Conceptualization, E.H. and J.C.; methodology, Y.Z.; formal analysis, X.Z.; writing—original draft preparation, E.H. and Y.Z.; writing—review and editing, J.C. All authors have read and agreed to the published version of the manuscript.

Funding: This research was funded by the National Natural Science Foundation of China (21205050), China Agriculture Research System (CARS-27-01A), and Natural Science Foundation of Jiangsu University (No. 12JDG038).

Conflicts of Interest: The authors declare no conflict of interest.

\section{References}

1. Otto, M. Staphylococcus aureus toxins. Curr. Opin. Microbiol. 2014, 17, 32-37. [CrossRef] [PubMed]

2. Gill, A.A.S.; Singh, S.; Thapliyal, N.; Karpoormath, R. Nanomaterial-based optical and electrochemical techniques for detection of methicillin-resistant Staphylococcus aureus: A review. Microchim. Acta 2019, 186, 114-133. [CrossRef] [PubMed]

3. Fujikawa, H. Prediction of detection time of staphylococcal enterotoxin A formed in hydrated batter mix. Food Control 2021, 121, 107559-107564. [CrossRef]

4. Yang, Y.C.; Hu, Z.; Shang, W.; Hu, Q.; Zhu, J.; Yang, J.; Peng, H.; Zhang, X.; Liu, H.; Cong, Y.; et al. Molecular and phenotypic characterization revealed high prevalence of multidrug-resistant methicillin-susceptible Staphylococcus aureus in chongqing, southwestern China. Microb. Drug Resist. 2016, 23, 241-246. [CrossRef] [PubMed]

5. McDonough, P.L.; Rossiter, C.A.; Rebhun, R.B.; Stehman, S.M.; Lein, D.H.; Shin, S. Prevalence of Escherichia coli O157:H7 from cull dairy cows in New York State and comparison of culture methods used during preharvest food safety investigations. J. Clin. Microbiol. 2000, 38, 318-322. 
6. Cheng, J.C.; Huang, C.L.; Lin, C.C.; Chen, C.C.; Chang, Y.C.; Chang, S.S.; Tseng, C.P. Rapid detection and identification of clinically important bacteria by high-resolution melting analysis after broad-range ribosomal RNA real-time PCR. Clin. Chem. 2006, 52, 1997-2004. [CrossRef]

7. Nagaraj, S.; Ramlal, S.; Kingston, J.; Batra, H.V. Development of IgY based sandwich ELISA for the detection of staphylococcal enterotoxin G (SEG), an egc toxin. Int. J. Food Microbiol. 2016, 237, 136-141. [CrossRef]

8. Rubaba, M.; Shahbazb, H.M.; Olaimatc, A.N.; Oh, D.H. Biosensors for rapid and sensitive detection of Staphylococcus aureus in food. Biosens. Bioelectron. 2018, 105, 49-57. [CrossRef]

9. Lu, L.; Chee, G.; Yamada, K.; Jun, S. Electrochemical impedance spectroscopic technique with a functionalized microwire sensor for rapid detection of foodborne pathogens. Biosens. Bioelectron. 2013, 42, 492-495. [CrossRef]

10. Cesewski, E.; Johnson, B.N. Electrochemical biosensors for pathogen detection. Biosens. Bioelectron. 2020, 159, 112214-112243. [CrossRef]

11. Yang, H.; Chen, H.; Cao, L.; Wang, H.; Deng, W.F.; Tan, Y.M.; Xie, Q.J. An immunosensor for sensitive photoelectrochemical detection of Staphylococcus aureus using $\mathrm{ZnS}-\mathrm{Ag}_{2} \mathrm{~S}$ / polydopamine as photoelectric material and $\mathrm{Cu}_{2} \mathrm{O}$ as peroxidase mimic tag Talanta 2020, 212, 120797-120805. [CrossRef] [PubMed]

12. Chinnadayyala, S.R.; Park, J.; Abbasi, M.A.; Cho, S. Label-free electrochemical impedimetric immunosensor for sensitive detection of IgM rheumatoid factor in human serum. Biosens. Bioelectron. 2019, 143, 111642-111649. [CrossRef]

13. Dutta, G.; Jallow, A.A.; Paul, D.; Moschou, D. Label-free electrochemical detection of S. mutans exploiting commercially fabricated printed circuit board sensing electrodes. Micromachines 2019, 10, 575. [CrossRef] [PubMed]

14. Han, E.; Li, X.; Zhang, Y.; Zhang, M.N.; Cai, J.R.; Zhang, X.A. Electrochemical immunosensor based on self-assembled gold nanorods for label-free and sensitive determination of Staphylococcus aureus. Anal. Biochem. 2020, 611, 113982-113989. [CrossRef] [PubMed]

15. Zhang, X.A.; Jiang, Y.J.; Zhu, M.C.; Xu, Y.W.; Guo, Z.M.; Shi, J.Y.; Han, E.; Zou, X.B.; Wang, D. Electrochemical DNA sensor for inorganic mercury(II) ion at attomolar level in dairy product using $\mathrm{Cu}$ (II)-anchored metal-organic framework as mimetic catalyst. Chem. Eng. J. 2020, 383, 123182-123190. [CrossRef]

16. Jiang, B.; Duan, D.; Gao, L.; Zhou, M.; Fan, K.; Tang, Y.; Xi, J.; Bi, Y.; Tong, Z.; Gao, G.F.; et al. Standardized assays for determining the catalytic activity and kinetics of peroxidase-like nanozymes. Nat. Protoc. 2018, 13, 1506-1520. [CrossRef]

17. Ma, E.; Wang, P.; Yang, Q.; Yu, H.; Pei, F.; Zheng, Y.; Liu, Q.; Dong, Y.; Li, Y. Electrochemical immunosensors for sensitive detection of neuron-specific enolase based on small-size trimetallic $\mathrm{Au} @ \mathrm{Pd} \wedge \mathrm{Pt}$ nanocubes functionalized on ultrathin $\mathrm{MnO}_{2}$ nanosheets as signal labels. ACS Biomater. Sci. Eng. 2020, 6, 1418-1427. [CrossRef]

18. Yan, Q.; Yang, Y.; Tan, Z.; Liu, Q.; Liu, H.; Wang, P.; Chen, L.; Zhang, D.; Li, Y.; Dong, Y. A label-free electrochemical immunosensor based on the novel signal amplification system of $\mathrm{AuPdCu}$ ternary nanoparticles functionalized polymer nanospheres. Biosens. Bioelectron. 2018, 103, 151-157. [CrossRef]

19. Liu, L.; Chao, Y.; Cao, W.; Wang, Y.; Luo, C.; Pang, X.; Fan, D.; Wei, Q. A label-free amperometric immunosensor for detection of zearalenone based on trimetallic Au-core/AgPt-shell nanorattles and mesoporous carbon. Anal. Chim. Acta 2014, 847, 29-36. [CrossRef]

20. Barman, S.C.; Hossain, M.F.; Yoon, H.; Park, J.Y. Trimetallic Pd@Au@Pt nanocomposites platform on -COOH terminated reduced graphene oxide for highly sensitive CEA and PSA biomarkers detection. Biosens. Bioelectron. 2018, 100, 16-22. [CrossRef]

21. Mo, F.; Xie, J.; Wu, T.; Liu, M.; Zhang, Y.; Yao, S. A sensitive electrochemical sensor for bisphenol A on the basis of the AuPd incorporated carboxylic multi-walled carbon nanotubes. Food Chem. 2019, 292, 253-259. [CrossRef]

22. Zhu, X.; Niu, X.; Zhao, H.; Tang, J.; Lan, M. Immobilization of superoxide dismutase on Pt-Pd/MWCNTs hybrid modified electrode surface for superoxide anion detection. Biosens. Bioelectron. 2015, 67, 79-85. [CrossRef]

23. Mohammadi, A.; Heydari-Bafrooei, E.; Mehdi Foroughi, M.; Mohammadi, M. Heterostructured Au/MoS 2 -MWCNT nanoflowers: A highly efficient support for the electrochemical aptasensing of solvated mercuric ion. Microchem. J. 2020, 158, 105154-105161. [CrossRef]

24. Zhou, X.; Qian, X.; Tan, X.; Ran, X.; Li, Z.; Huang, Z.; Yang, L.; Xie, X. Water-soluble pillar arene functionalized PdPt porous core-shell octahedral nanodendrites to construct highly sensitive and robust neuron-specific enolase immunosensor by host-guest chemistry assisted catalytic amplification. Anal. Chim. Acta 2019, 1068, 18-27. [CrossRef]

25. Xu, Q.; Jia, H.; Duan, X.; Lu, L.; Tian, Q.; Chen, S.; Xu, J.; Jiang, F. Label-free electrochemical immunosensor for the detection of prostate specific antigen based three-dimensional Au nanoparticles/ $\mathrm{MoS}_{2}$-graphene aerogels composite. Inorg. Chem. Commun. 2020, 119, 108122-108131. [CrossRef]

26. Cui, R.; Han, Z.; Zhu, J.J. Helical carbon nanotubes: Intrinsic peroxidase catalytic activity and its application for biocatalysis and biosensing. Chem-Eur. J. 2011, 17, 9377-9384. [CrossRef] [PubMed]

27. Tan, Z.L.; Dong, H.; Liu, Q.; Liu, H.; Zhao, P.; Wang, P.; Li, Y.; Zhang, D.; Zhao, Z.; Dong, Y. A label-free immunosensor based on PtPd NCs@MoS 2 nanoenzymes for hepatitis B surface antigen detection. Biosens. Bioelectron. 2019, 142, 111556-111565. [CrossRef] [PubMed]

28. Wang, J.E.; Gao, J.Q.; Liu, D.J.; Han, D.X.; Wang, Z.X. Phenylboronic acid functionalized gold nanoparticles for highly sensitive detection of Staphylococcus aureus. Nanoscale 2012, 4, 451-454. [CrossRef] [PubMed]

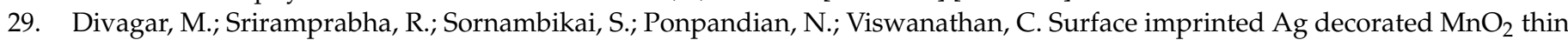
film electrodes for the synergic electrochemical detection of bacterial pathogens. J. Electrochem. Soc. 2019, 166, G1-G9. [CrossRef] 
30. Borsa, B.A.; Tuna, B.G.; Hernandez, F.J.; Hernandez, L.I.; Bayramoglu, G.; Arica, M.Y.; Ozalp, V.C. Staphylococcus aureus detection in blood samples by silica nanoparticle-oligonucleotides conjugates. Biosens. Bioelectron. 2016, 86, 27-32. [CrossRef]

31. Pebdeni, A.B.; Hosseini, M. Fast and selective whole cell detection of Staphylococcus aureus bacteria in food samples by paper based colorimetric nanobiosensor using peroxidaselike catalytic activity of DNA-Au/Pt bimetallic nanoclusters. Microchem. J. 2020, 159, 105475-105484. [CrossRef]

32. Yang, Z.; Wang, Y.; Zhang, D. A novel multifunctional electrochemical platform for simultaneous detection, elimination, and inactivation of pathogenic bacteria based on the Vancomycin-functionalised AgNPs/3D-ZnO nanorod arrays. Biosens. Bioelectron. 2017, 98, 248-253. [CrossRef] [PubMed]

33. Khateb, H.; Klös, G.; Meyer, R.L.; Sutherland, D.S. Development of a label-free LSPR-Apta sensor for Staphylococcus aureus detection. ACS Appl. Bio Mater. 2020, 3, 3066-3077. [CrossRef]

34. Zhao, M.; Yao, X.L.; Liu, S.J.; Zhang, H.; Wang, L.L.; Yin, X.C.; Su, L.H.; Xu, B.C.; Wang, J.L.; Lan, Q.X.; et al. Antibiotic and mammal IgG based lateral flow assay for simple and sensitive detection of Staphylococcus aureus. Food Chem. 2021, 339, 127955-127963. [CrossRef] 